\title{
Broad ligament ectopic pregnancy: a dilemma to diagnose
}

\section{Shweta Mittal*, Vinita Gupta, Dolly Chawla, Seema Pundir}

Department of Obstetrics and Gynecology, Dr. Baba Saheb Ambedkar Medical College and Hospital, Rohini, Delhi, India

Received: 15 March 2017
Accepted: 07 April 2017

\section{*Correspondence:}

Dr. Shweta Mittal,

E-mail: mittalshw@gmail.com

Copyright: $@$ the author(s), publisher and licensee Medip Academy. This is an open-access article distributed under the terms of the Creative Commons Attribution Non-Commercial License, which permits unrestricted non-commercial use, distribution, and reproduction in any medium, provided the original work is properly cited.

\begin{abstract}
Broad ligament ectopic pregnancy is a rare and serious form of extrauterine pregnancy with a high risk of maternal mortality. There are no specific clinical features. Ultrasonography may help in diagnosis but definitive diagnosis is made only during surgery. A 20 -year-old woman with previous 2 abortions presented with acute abdomen. She had no history of amenorrhoea but there was history of two episodes of bleeding in the last month at an interval of 14 days, each episode lasting for two-three days. The last episode of bleeding was 10 days back. Her urine pregnancy test was done and it was positive. There was marked abdominal tenderness with guarding and rigidity. Per vaginal examination revealed marked tenderness in the right fornix and cervical motion tenderness, uterus size could not be assessed due to tenderness. It was diagnosed as a case of ruptured ectopic pregnancy. Since she was haemodynamically unstable, emergency laparotomy was done. She had a right sided broad ligament ectopic pregnancy which had ruptured. The tissue was completely removed and haemostatic sutures were taken. High index of clinical suspicion, early diagnosis and prompt surgery is the key to management.
\end{abstract}

Keywords: Broad ligament, Ectopic pregnancy, Laparotomy

\section{INTRODUCTION}

Ectopic pregnancy is a type of pregnancy that occurs outside the normal uterine cavity. Fallopian tube is the most common site of ectopic pregnancy (95\% cases) and abdominal account for $1 \% .^{1}$ Ectopic pregnancy in the broad ligament is a retroperitoneal abdominal pregnancy, in which the foetus or gestational sac develop within the leaves of the broad ligament. ${ }^{2}$ It is a rare and serious form of extrauterine pregnancy. It has a reported incidence of 1 in 183,900 pregnancies and occurs in about 1 in 245 ectopic pregnancies. ${ }^{3}$ The maternal mortality rate has been reported to be as high as $20 \% .^{4}$ This is because of massive haemorrhage from partial or total placental separation or rupture of gestational sac into peritoneal cavity. For an abdominal pregnancy, to reach advanced stage of gestation with viable foetus is very uncommon. In recent years, more and more patients were diagnosed in first trimester. There are no specific clinical features for this rare form of ectopic pregnancy to enable diagnosis to be made preoperatively. It thus remains a major diagnostic challenge for clinicians. Definitive diagnosis is made only on surgical exploration. Here we are describing a case of ruptured broad ligament ectopic pregnancy at a very early gestational age that was diagnosed on laparotomy. In our institution, 100 ectopic pregnancies are being operated in one year and this was the only case reported till date.

\section{CASE REPORT}

A 20-year-old woman with previous 2 abortions presented on 6th February 2017 with generalized abdominal pain since few hours. She had no complain of bleeding per vaginum. She had no history of amenorrhoea but there was history of two episodes of bleeding in the last month at an interval of 14 days (14th January and 28th January), each episode lasting for twothree days. The last episode of bleeding was 10 days back. Her urine pregnancy test was positive on the day of 
admission. She had been married for three years and had conceived spontaneously. She had a spontaneous abortion at 6 weeks amenorrhoea one and half years back and another first trimester spontaneous abortion 8 months back in which check curettage was done. Her past history and family history were unremarkable.

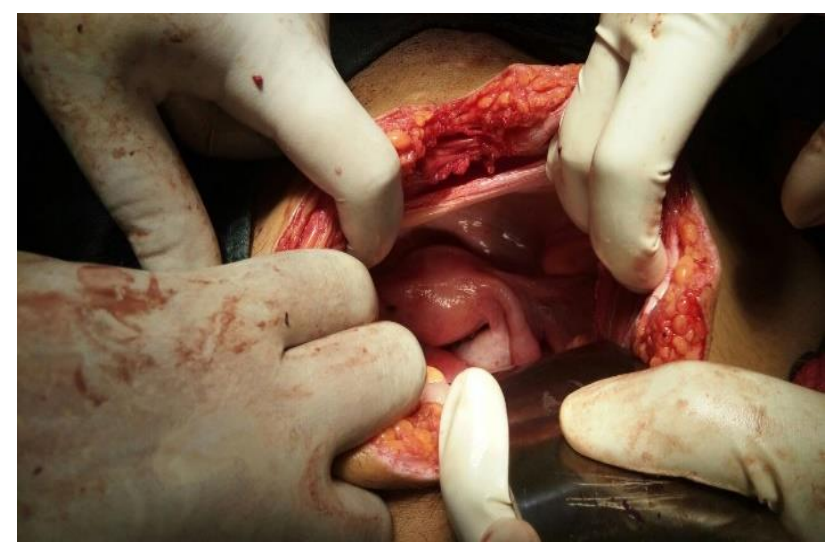

Figure 1: Normal uterus and bilateral fallopian tubes and ovaries.

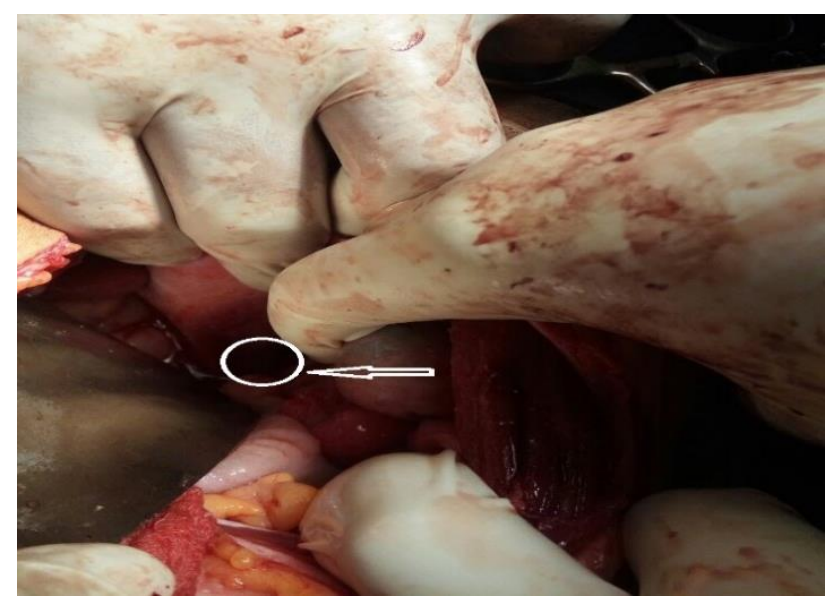

Figure 2: A small focus of ectopic pregnancy on the posterior side of the right sided broad ligament.

On examination, she was distressed and pale. Her pulse rate was 110/minute and blood pressure was 106/68 $\mathrm{mmHg}$. Per abdominal examination revealed marked tenderness, guarding and rigidity. Uterus was not palpable. Per vaginal examination revealed marked tenderness in the right fornix and cervical motion tenderness, uterus size could not be assessed due to tenderness. Culdocentesis was positive. Her haemoglobin was $8.8 \mathrm{~g} / \mathrm{dl}$ and blood group was $\mathrm{O}+$. Ultrasonography could not be done as the patient was haemodynamically unstable.

The decision for emergency laparotomy was taken due to high clinical suspicion of ruptured ectopic pregnancy. Two units of blood were arranged. Intraoperatively, around $500 \mathrm{ml}$ of blood was present in the peritoneal cavity. Both the fallopian tubes and ovaries and uterus were found normal (Figure 1). After intensive search for the focus of ectopic, a small around $1 \mathrm{~cm}$ rent was found on the posterior side of right sided broad ligament which was bleeding and through which some tissue was protruding out (Figure 2). The tissue was completely removed and sent for histopathological examination and haemostatic sutures were taken. Histopathology report confirmed the tissue as products of conception. Patient had uneventful recovery and was discharged on day 5 . She was doing well on follow-up.

\section{DISCUSSION}

Broad ligament ectopic pregnancy is a rare but life threatening condition. Maternal mortality is as high as $20 \% .^{4}$ It is either due to primary implantation of the zygote on the broad ligament or followed by secondary implantation from the fallopian tube, ovary or other peritoneal surface. In this case primary focus of ectopic pregnancy could not be found elsewhere except the broad ligament.

The risk factors include a history of secondary infertility, use of assisted reproduction technologies, pelvic inflammatory disease, use of intrauterine devices, use of progesterone only pills, a previous history of ectopic pregnancy and endometriosis. ${ }^{5}$ There was no apparent risk factor in this case. The clinical presentation of broad ligament ectopic pregnancy is highly variable and can range from asymptomatic early ectopic pregnancy to rupture in labour at term. Dull lower abdominal pain during early gestation is common. This has been attributed to the placental separation, tearing of broad ligament and small peritoneal haemorrhage. ${ }^{6,7}$ Vaginal bleeding is also a common feature reported in up to half of the patients. ${ }^{8}$ In this case, she presented with severe abdominal pain with guarding and rigidity and no vaginal bleeding, making the differential diagnosis towards ruptured ectopic pregnancy, torsion of ovarian cyst or any surgical cause of acute abdomen. As her urine pregnancy test was positive, so the provisional diagnosis of ruptured ectopic pregnancy was made.

Ultrasound is the investigation of choice for diagnosis. Magnetic resonance imaging (MRI) provides additional information for evaluating the extent of uterine and mesenteric involvement. ${ }^{9}$ The old saying "in a reproductive age group lady with atypical amenorrhoea, pain abdomen and bleeding, think of an ectopic pregnancy", still holds good for diagnosis of ectopic. Broad ligament ectopic pregnancy is difficult to diagnose on imaging. In this case, ultrasonography could not be done due to haemodynamically unstable condition.

The management is exploratory laparotomy. However, stable patients with early gestation can be considered for laparoscopic removal for small broad ligament pregnancies. ${ }^{10}$ Our patient was immediately taken for laparotomy with excision of the mass and had uneventful recovery. 


\section{CONCLUSION}

Broad ligament ectopic pregnancy is not only rare but also the diagnosis is a challenge. High index of clinical suspicion, early diagnosis and prompt surgery is the key to management.

Funding: No funding sources Conflict of interest: None declared

Ethical approval: Not required

\section{REFERENCES}

1. Bobyer J, Coste J, Fernandez H, Pouly JL, JobSpira N. Sites of ectopic pregnancy: a 10 Year population based study of 1800 cases. Hum Reprod. 2008;17:3224-30.

2. Phupong V, Lertkhachonsuk $R$, Triratanachat $S$, Sueblinvong T. Pregnancy in the broad ligament. Arch Gynecol Obstet. 2003;268:233-5.

3. Chia KV, Fayle RJS, Ferriman E. Intraligamentary pregnancy. J Obstet Gynaecol. 1993;13:254.

4. Alto WA. Abdominal pregnancy. Am Fam Physician. 1990;41:209-14.
5. Cordero DR, Adra A, Yasin S, O'Sullivan MJ. Intraligamentary pregnancy. Obstet Gynecol Surv. 1994;49:206.

6. Paterson WG, Grant KA. Advanced intraligamentous pregnancy. Report of a case, review of the literature and a discussion of the biological implications. Obstet Gynecol Surv. 1975;30:715-26.

7. Vierhout ME, Wallenburg HC. Intraligamentary pregnancy resulting in a live infant. Am J Obstet Gynecol. 1985;152:878-9.

8. Hallatt JG, Grove JA. Abdominal pregnancy: a study of twenty-one consecutive cases. Am J Obstet Gynecol. 1985;152:444-9.

9. Malian V, Lee JH. MR imaging and MR angiography of abdominal pregnancy with placental infarction. AJR Am J Roentgenol. 2001;177:1305-6.

10. Pisarka MD, Casson PR, Moise KJ, Di Maio DJ, Buster JE, Carson SA. Heterotropic abdominal pregnancy treated at laparoscopy. Fertil Steril. 1998;70:159-60.

Cite this article as: Mittal S, Gupta V, Chawla D, Pundir S. Broad ligament ectopic pregnancy: a dilemma to diagnose. Int $\mathbf{J}$ Reprod Contracept Obstet Gynecol 2017;6:2109-11. 